\title{
Multidimensional Parents' Action on Adolescents Academic Achievement in Malaysia
}

\author{
William Koh Siaw Yen (Corresponding author) \\ School of Educational Studies, University Science Malaysia \\ 11800 Minden, Penang, Malaysia \\ Tel: 60-16-477-8220 E-mail: william8m@yahoo.com.my
}

Ong Saw Lan

School of Educational Studies, University Science Malaysia

11800 Minden, Penang, Malaysia

Tel: 12-512-447-446Ｅ-mail: osl@usm.my

\begin{abstract}
This paper is an initial examination of the norm activities of what parents do at home to their adolescence school-going children and eventually how these factors contribute to their academic achievement. The notion that parental involvement was crucial to their children academic achievement and well being was reinvestigated by utilizing a different approach - parents' actions. The end product of the research was a reliable and valid instrument SPAQ1 (Students' Parents Actions Questionnaire I). SPAQ1 also exhibited a good model fit. Recommendations for future research were forwarded.
\end{abstract}

Keywords: Confirmatory Factor Analysis, Measurement model, Parents Actions Questionnaire

\section{Parents and Adolescent}

The parenting process is linked to children behavior. Though this may be seen as an inclination towards 'Skinnerian' epistemology but what parents do with their children may have psychologically affected them to react differently. Many researchers had investigated the relationship of parental involvement with their children academic achievement through isolated independent variables such as helping out with homework or motivation with academic achievement. Thus, coverage of more global dimensions of parental involvement in academic achievement may provide a better picture. Hence, this article describes the development of an instrument (SPAQ1) to tap into more comprehensive dimensions of parental actions at home that relate to adolescents' academic achievement. Briefly, the construction of SPAQ1 scale comprised of three phases. In the first phase, the dimensions of SPAQ1 were delineated through in depth literature reviews based on various theories. A hypothetical measurement model set up from the review was then subjected to content evaluation by selected experts. Items were revised based on inputs of experts. SPAQ1 was then translated to Malay language by employing the committee approach method (Vijver \& Leung, 1997).

Finally, two pilot studies were carried out to ensure good psychometric properties of the scale. The first pilot study was to obtain information regarding the suitability and readability of the items while the second one was to collect data for use in statistical tools to provide reliable and valid evidence of the instrument

The purposes of this article are therefore (1) to report the reliability and validity evidence for SPAQ1, and (2) to formulate recommendations for future research.

\section{Literature Review Stage}

An enormous number of literatures available were related to parental involvement. Many have reported and discussed the importance of parental involvement for early childhood and adolescents' development. Two pertinent aspects which were of interest were academic achievement and discipline in school. Various researches had looked at constructs such as parents' aspiration (McLaughlin, 2006), assisting in homework (Cooper, Lindsay \& Nye, 2000), attending schools' activities (Epstein, Simon \& Salinas, 1997) in relation with academic achievement and discipline. Most of these studies relied on parents' responses of their involvement with their children. Responses elicited from parents may be biased as they might have the tendency to give only universally accepted responses. Hence, the alternative of using a questionnaire like SPAQ1 that source responses from students on their parents' actions may be able to elicit more concrete evidence regarding parental actions. The accuracy of self-report response by children older than 11 years of age has been recognized as acceptable (Fallon 
\& Bowles, 1997).

\subsection{Conceptual and Theoretical Framework}

Based on the literature reviewed, eight independent latent variables were conceptualized to represent the parental actions' dimensions or constructs. These dimensions were based on the ecological system theory (Bronfenbrenner, 1977), social learning theory (Bandura, 1977) and social cognitive theory (Bandura, 1989), attachment theory (Bowlby, 1969/1997), social bonding theory (Hirschi, 1969) and overlapping spheres of influence (Epstein, Simon \& Salinas, 1997).

Bronfenbrenner (1977) had forwarded the idea that the surrounding or ecological circle which was the closest to the entity (in this case, student) would exert the most influence on the entity. In the Asian context, particularly Malaysia, parents continues to play a very important role in adolescence's lives. Certainly, the changing society diminishes their influence on the child. Nevertheless, an insightful empirical investigation on the parents' actions towards children academic achievement in Malaysia would be of interest to the public. As implied in Hong \& Ho (2005), Asian parents tend to support strongly but quietly from home on motivating their children to excel. The theoretical framework for this study was shown in Figure 1.

[Insert Figure 1 here]

\subsection{Generating Item Pool}

An initial item pool of 57 items was synergized and created to measure the eight underlying hypothesized dimensions. These items were subjected to evaluation by seven experts. The experts were selected based on their field of expertise in their research and published articles. They were asked to judge and evaluate the accuracy of the items in measuring the constructs through email correspondence in early February 2009. Six sets of ratings (by six judges) were returned with the final feedback received in May 2009.

Based on the feedback received, double-barreled items were split into two separate items. E.g., Item W1 for the Warmth (WARM) construct, "My parents discuss with me at least once a week about the daily issue and about my study at school" was split into Item W1, "How often do your parents discuss with you about the daily issues?" and Item W2, "How often do your parents discuss with you about your study at school?" Four items were added to the questionnaire. Two items were added to the Homework (HWK) construct; Item H6, "My parents insist that I finish all my homework first before enjoying the time with family or friends" and Item H7, "My parents encourage me to give the best in doing my homework". The other two items were for the Religiosity (REL) construct; R6, "My parents want me to practice my religion" and R7, "How often do your parents discuss religious matters with you?"

In addition, some scales were converted to the five point frequency type Likert scale. All items were mapped to the eight hypothesized operational constructs as shown in Figure 2. The items were then translated to the Malay language using the committee approach method (Vijver \& Leung, 1997). The procedures were explained briefly in the following section.

[Insert Figure 2 here]

\subsection{Translation of SPAQ1}

SPAQ1 was translated to the Malay language by a six members committee consisting of bilingual teachers cum parents. During the translation, the researcher first read aloud the definition of the construct. Each of the 62 items was then given and translation was done by individual members. Agreement among members was negotiated before the final translation was accepted. The SPAQ1 BM version was finalized after two group discussion sessions with all the committee members.

The first pilot study was carried out using the SPAQ1 BM to test the readability, suitability and understandability of the items with 26 Form Four students which will be the target sample of this study. Some corrections were needed for a few items as the students found them confusing.

\section{Second Pilot study}

For this stage of the study, empirical data were needed to carry out item analysis. Convenience sampling was used to administer the questionnaire. A total of 477 Form Four secondary students (Grade 10) participated with the permission granted by the schools administrator. The characteristics of the sample used were shown in Table 1. The grade point average (GPA) of ' 1 ' in the public examination ('Penilaian Menengah Rendah') indicates highest academic achievement. The GPA ranged from ' 1 ' to ' 5 ' with ' 5 ' as the weakest or very low achiever.

[Insert Table 1 here] 


\subsection{Data Preparation and Data Screening}

After data preparation and data screening, only 400 set of responses were usable. The students' responses were manually scanned for scoring errors, acquiescent effect (Cronbach, 1946), missing values, and unsuitable samples. Acquiescence is defined as the tendency to agree (or disagree) with items regardless of their content (Couch \& Keniston, 1960). Hence, acquiescence was also a threat to the analysis as it may produce extreme outliers. Responses with one scale answer throughout the whole questionnaire were omitted manually. Thirty five students who were not staying with their biological parents were not given the questionnaire. Eight sets of responses were taken out for acquiescent effect, 31 incomplete responses and eight irrelevant sample (they were not staying with their biological parents) were not included in the analysis. With 15 students absent from school, the number of usable response sets was further reduced to 380 . Hence the initial usable rate was $79.66 \%$ of the total respondents.

Next, univariate outliers, multivariate outliers, skewness and kurtosis, linearity, singularity and multicollinearity were checked in order to fulfill the normality assumption of most statistical analysis including structural equation modeling (SEM). Seven multivariate outliers were detected using Mahalanobis coefficient $\mathrm{D}^{2}\left(\chi^{2}>26.124, \mathrm{df}=8\right.$, $p<0.001$ ). Finally 373 response sets were used in the analyses. The reliability and validity evidence were provided from statistical analysis using SPSS 15.0 and AMOS 16.0.

\subsection{Reliability and Validity Analysis of SPAQ1}

Reliability was established by calculating alpha coefficients, inter-item correlation and item-total correlation, using SPSS 15.0. Items that did not meet the set criteria of $\alpha>0.60$, inter-item correlations which have about the same magnitude within $0.20-0.70$, standard deviation $\sigma>1.10$ (on a 5 point Likert scale), item-total correlations of $>0.30$ and standardized residual covariance $>|2.00|$ were eliminated. The summarized results were as shown in Table 2.

[Insert Table 2 here]

With reference to Table 2, Aspiration (ASP) dimension consisted of seven items initially. Two items were deleted as the standard deviation (SD) did not meet the cut off value of SD $>1.10$ implicating a small spread of variance and the factor loading for A2 and A6 were below the set criteria of $\lambda>0.60$. The standardized residual covariance $(\delta)$ between A2 and A6 as shown in the standardized residual covariance column in Table 2 indicated the highest value within the dimension. This added evidence to support items deletion. The internal consistency of the ASP dimension was regarded as high with $\alpha=0.86$. The values of the inter-item correlations $\left(\mathrm{r}_{\mathrm{i}-\mathrm{i}}\right)$ ranged from 0.30 to 0.62 which implied that the items were amply associated. The item-total correlations $\left(\mathrm{r}_{\mathrm{i}-\mathrm{t}}\right)$ ranged from 0.51 to 0.72 , indicating that these items were mainly measuring the same underlying construct.

For the Homework (HWK) dimension, Item $\mathrm{H} 3$ and $\mathrm{H} 7$ were problematic as shown in Table 2. Item $\mathrm{H} 7$ violated both the SD and factor loading criteria. The standardized residual covariance between $\mathrm{H} 7$ and $\mathrm{H} 1$ was $\delta=2.34$ (slightly exceeding the criteria of $\delta<|2.00|$ ). The factor loading of Item H3 was $\lambda=0.33$ which was below the set criteria of $\lambda>0.60$. The value of $\mathrm{SD}=1.03$ for $\mathrm{H} 7$ was below the cut off value of $\mathrm{SD}>1.10$. The inter-item correlations ranged between 0.21-0.71, indicating well related items. The item-total correlations for HWK ranged from 0.32 to 0.64 which met the cut off value of $>0.30$. The overall internal consistency of HWK was $\alpha$ $=0.84$.

The third dimension, Conduciveness (COND) with $\alpha=0.71$, showed four items CD2, CD4, CD5 and CD7 which were probable items for deletion. Item $\mathrm{CD} 2$ exhibited $\mathrm{SD}=1.04, \lambda=0.49$, whereas $\mathrm{CD} 4$ yielded a low factor loading of $\lambda=0.40$. Item CD5 had the lowest factor loading, $\lambda=0.30$ and $C D 7, \lambda=0.44$. CD5 also exhibited the lowest item-total correlation which was labeled as $(\mathrm{CD} 5)_{\mathrm{L}}=0.24$. All these $\lambda$ values were less than 0.60 . However, the inter-item correlations ranged from 0.04-0.45, which was lower than the criteria of between $0.20-0.60$. The standardized residual covariance did not show any anomaly. However, Item CD2 was retained for further investigation with AMOS 16.0 as a minimum of four to six items were needed for identification using structural equation modeling in AMOS 16.0. Deleting CD2 from this dimension would result in under-identification due to insufficient items. Since CD2 exhibited the least violation, it was retained. This decision was made based on the recommendation that, if necessary, a poor performing item can still be retained to satisfy statistical analysis requirement (Hair, Black, Cabin, Anderson \& Tatham, 2006).

The fourth dimension of Religiosity (REL) has a coefficient alpha, $\alpha=0.91$. The factor loadings of the seven individual items ranged from $\lambda=0.71$ to $\lambda=0.87$, hence all the items fulfilled the factor loadings criteria of $\lambda>$ 0.60 . Based on the $\mathrm{SD}$ value, $\mathrm{R} 4$ yielded $\mathrm{SD}=1.14$ which was the lowest among all the items. The standardized residuals covariance of Item R4 and R2 was $\delta=1.53$ which was the highest though still within the cut off value of 
$\delta<|2.00|$. Hence, item R4 was considered for exclusion. The inter-item correlations were $0.47-0.73$ and the item-total correlations ranged from 0.67 to 0.83 . This construct exhibited a strong association among the seven items.

The Control (CONT) dimension consisted of 12 items has an overall coefficient alpha, $\alpha=0.86$. Factor loadings ranged from $\lambda=0.46$ to $\lambda=0.72$, inter-item correlations ranged from $0.16-0.65$ and item-total correlation ranged from 0.42 to 0.67 indicating a fair association among the items which were measuring the underlying construct. However, items C1, C2, C3, C6, C7, C8, and C12 were considered for deletion as each of the items has factor loading lower than 0.60 . The standardized residuals covariance exceeded the value of $\delta=|2.00|$ in five pairs of items. Item $\mathrm{C} 1$ and $\mathrm{C} 2$ recorded a value of $|\delta|=3.28$, between $\mathrm{C} 1$ and $\mathrm{C} 4,|\delta|=3.57$, between $\mathrm{C} 4$ and $\mathrm{C} 12,|\delta|=3.03$, between $\mathrm{C} 6$ and $\mathrm{C} 12,|\delta|=3.91$ and lastly between $\mathrm{C} 7$ and $\mathrm{C} 8$ with a value of $|\delta|=3.29$ (refer Table 2).

Overall internal consistency for the Motivation (MOV) dimension was $\alpha=0.86$. There were eight items measuring this construct with factor loadings ranging from $\lambda=0.43$ to $\lambda=0.81$. The item-total correlations ranged from 0.41 to 0.71 and the inter-tem correlations ranged from 0.15-0.75. Item M3, M5 and M6 were considered for deletion as the factor loadings were below the criteria of $\lambda=0.60$. Item M3 recorded a $\lambda=0.55$, M5 with $\lambda=0.43$ and finally M6 with $\lambda=0.51$. Furthermore, for M6 the $\mathrm{SD}=0.94$ which was below the set criteria of $>1.10$. The standardized residual covariance between M3 and M6 was $|\delta|=3.23$. This clearly supported the deletion of items M3, M5 and M6.

The Warmness (WARM) dimension consisted of eight items with an overall internal consistency of $\alpha=0.83$. The factor loadings of W5 $(\lambda=0.57)$, W6 $(\lambda=0.58)$ and W8 $(\lambda=0.41)$ were all below the set criteria of $\lambda>0.60$. The SD of W5, W6, and W8 were 1.08, 0.77 and 1.06 respectively which were below the SD criteria set at the value of 1.10. Meanwhile the standardized residual covariance between $\mathrm{W} 1$ and $\mathrm{W} 2$ was $|\delta|=3.14$, W6 and W8 was $|\delta|=2.28$, W5 and W6 was $|\delta|=1.77$, W5 and W2 was $|\delta|=1.47$. Though $\mathrm{W} 1$ and $\mathrm{W} 2$ yielded $|\delta|=3.14$ which violated the cut off value, the other properties were within the specified ranges. Hence, these two items were retained for further analyses.

The Conflict (CONF) dimension recorded the lowest Cronbach's alpha value, $\alpha=0.56$. It consisted of six items and the factor loadings ranged from $\lambda=0.30$ to $\lambda=0.53$. Due to the fact that all the factor loadings in this dimension were below the set criteria of $\lambda>0.60$, only the item with the lowest factor loading, Item X4 $(\lambda=0.30)$ was considered for deletion. The standardized residual covariance between X4 and X6 was $|\delta|=2.11$, had violated the specified value and this supported the deletion of item X4 as well. Further item deletion was reassessed with confirmatory factor analysis (CFA) using AMOS 16.0.

The standardized residual covariance for each dimensions ranged from $|0.00|$ to a maximum of $|3.91|$. Residuals of items more than $|2.00|$ will be considered for deletion (Joreskog \& Sorbom, 1984). Based on the analyses results, the combination of the various statistical measures were taken into consideration in item elimination decision making. A large enough standard deviation $(\sigma>1.10)$, factor loadings $(\lambda>0.6)$, inter-item correlations $\left(0.2<\mathrm{r}_{\mathrm{i}-\mathrm{i}}<0.6\right)$, item-total correlations $\left(\mathrm{r}_{\mathrm{i}-\mathrm{t}}>0.3\right)$, standardized residual covariance $(\delta<|2.00|)$, and goodness of fit indices were considered when making the decision for item elimination. Due to space constraint, only the standardized residual covariances which exceeded the set criteria were presented in Table 2. The items which were listed in the table were items considered for deletion.

Negative item was not used in this instrument. As suggested by Blunch (2008), negation in items should be avoided. This was because negated items may cause confusion to the respondents and on the other hand, researcher might forget to reverse the item scores before doing an analysis. There was also possibility that the respondents tend to miss or failed to see the negation in the item. Item having positive and negative correlations to other items within the construct should be discarded as well.

Internal consistency for each constructs was assessed using Cronbach's alpha. A second estimation of the internal consistency of the solution was the squared multiple correlations (SMC) of the factor scores predicted from scores on the observed variables. High SMC indicates stability of factor in that the observed variables account for a substantial variance in the factor scores and is considered a viable assessment of internal consistency (Bollen, 1989; Tabachnick \& Fidell, 2001). Further assessment using confirmatory factor analysis was utilized to validate convergent validity of each item to its related construct. This was explained in the following section.

\subsection{Item Deletion Decision using Structural Equation Modeling}

The pool of items selected was further assessed for their goodness of fit using AMOS 16.0 (Arbuckle, 2007). Each of the constructs and their related items were evaluated individually. Figure 3 illustrated an example of the 
graphical analysis interface using AMOS for the ASP construct. This was done in lieu with what was suggested by Lee (2007) which claimed that model fit had become a compulsory criterion that researchers will have to cope with in order to make variable selection or scale construction more appropriate. Item A2 and A6 were deleted based on the factor loading $(\lambda<0.60), \mathrm{R}^{2}(\mathrm{SMC})$ which were below 0.40 and an inspection of the standardized residual covariance showed quite a substantial error involved $(\delta=2.47)$. The smaller the values of the standard deviation $(\mathrm{SD}<1.10)$ also indicated that the variance spread of the items were not sufficient. By using CFA assessment on the individual model, it clearly showed a good fit when the three items were deleted. The indices were as follow.

[Insert Figure 3 here]

A chi-square over the degree of freedom value, $\chi 2 / \mathrm{df}=1.956$ shows a good fit. All the other indices such as the Adjusted Goodness of fit index (AGFI=0.976), Bollen's Incremental Fit Index (IFI=0.997), Tucker Lewis Index (TLI=0.990), Bentler's Comparative Fit Index ( $\mathrm{CFI}=0.997$ ) were well above the criteria value of $>0.90$ (Hair, et al.,2006). The Root Mean Residual (RMR $=0.021$ ) which was far below the criteria of $<0.05$ and Parsimony Normed Fit Index (PNFI=0.331) was also good as the value was around 0.5. The root mean square error of approximation (RMSEA $=0.049$ ) which was far below the criteria $<0.05$ to indicate a good fit. Table 3 showed the comparison of the initial goodness of fit indices (GOF) before item deletion and the final GOF after the deletion processes were carried out.

Factor loadings of item $\mathrm{H} 3(\lambda=0.33)$ and $\mathrm{H} 7(\lambda=0.58)$ were below the criteria of $\lambda>0.60$. The SMC of $\mathrm{H} 3\left(\mathrm{R}^{2}=\right.$ $0.11)$ and $H 7\left(R^{2}=0.34\right)$ were below the set criteria of $>0.40$. The $\mathrm{SD}$ of $\mathrm{H} 7$ was 1.03 which was below the cutting point of 1.10 set by the researcher. Though H6 fulfilled all the criteria except for its $\mathrm{SMC}\left(\mathrm{R}^{2}=0.37\right)$, further assessment using CFA suggested its deletion. The Homework (HWK) construct exhibited a good fit with $\chi 2 / \mathrm{df}=2.127, \mathrm{AGFI}=0.975, \mathrm{IFI}=0.996, \mathrm{TLI}=0.988, \mathrm{CFI}=0.996$, all were well above the criteria value of $>0.90$. The $\mathrm{RMR}=0.025$ and $\mathrm{PNFI}=0.331$ which were good as the values were around 0.5 . The RMSEA $=0.053$ which was near the criteria $<0.05$ indicated a good fit too. Four items in the Conducive (COND) construct exhibited poor item characteristics, hence CD2 $(\lambda=0.49, \mathrm{SD}=1.04, \mathrm{R} 2=0.24), \mathrm{CD} 4(\lambda=0.40, \mathrm{R} 2=0.16), \mathrm{CD} 5(\lambda=0.30$, $\left.\mathrm{R}^{2}=0.09\right)$ and $\mathrm{CD} 7\left(\lambda=0.44, \mathrm{R}^{2}=0.19\right)$ were considered for deletion. However, when CD2 was included in the CFA, it exhibited an overall good fit, with $\chi 2 / \mathrm{df}=0.072$, AGFI $=0.999$, IFI $=1.000, \mathrm{TLI}=1.000, \mathrm{CFI}=1.000$ ) were well above the criteria value of $>0.90$ and $\mathrm{RMR}=0.005$ which was far below the criteria of $<0.05$ and $\mathrm{PNFI}=0.333$ which was good as the value was around 0.5 . The RMSEA $=0.000$ was far below the criteria $<0.05$ to indicate an excellent fit too. Therefore, Item CD2 was retained in the measurement model.

Though none of the seven items in Religiosity (REL) showed any inferiority in its reliability analysis (refer Table 2), item R2 had the lowest $\lambda=0.71$ and the highest $|\delta|=1.53$ comparatively. Hence, it can be considered for deletion. In order to minimize the number of indicators as to make the instrument more feasible in term of practicality, weaker items were deleted based on CFA. Finally item R2, R4 and R5 were eliminated and the model exhibited $\chi 2 / \mathrm{df}=3.457$, AGFI $=0.957$, IFI $=0.994$, TLI $=0.983, \mathrm{CFI}=0.994$ which were well above the criteria value of $>0.90, \mathrm{RMR}=0.025$ which was far below the criteria of $<0.05$ and $\mathrm{PNFI}=0.331$ which was good as the value was near to 0.5 . The RMSEA $=0.078$ which was still within the criteria $<0.10$ to indicate an acceptable fit.

Control or supervision by parents (CONT) had the most number of indicators in the item pool (a total of 12 items). An early probe into the factor loadings, indicated seven probable items for deletion (refer Table 2). Items $\mathrm{C} 1, \mathrm{C} 2, \mathrm{C} 3, \mathrm{C} 6, \mathrm{C} 7, \mathrm{C} 8$ and $\mathrm{C} 12$, all with $\lambda<0.60$ and $\mathrm{R}^{2}<0.40$. Besides, the standardized residuals covariance, $\delta>|2.00|$ were seen in items $\mathrm{C} 1, \mathrm{C} 2, \mathrm{C} 4, \mathrm{C} 6, \mathrm{C} 7, \mathrm{C} 8$ and $\mathrm{C} 12$. A stepwise deletion was executed to find a good fit. Finally, C1, C9, C10, C11 and C12 were maintained in the pool. Deletion of one item from a pair of items which exhibited high residual correlation was carried out one after another and the results of GOF compared. The best model fit was selected. The individual construct exhibited $\chi 2 / \mathrm{df}=1.953$, AGFI $=0.973, \mathrm{IFI}=0.991$, $\mathrm{TLI}=0.985, \mathrm{CFI}=0.991$ were well above the criteria value of $>0.90$ and $\mathrm{RMR}=0.046$ which was far below the criteria of $<0.05$ and PNFI $=0.58$ was around 0.50 . The RMSEA $=0.049$ which was still within the criteria $<0.05$, indicated a good fit.

The items in Motivation (MOV) particularly, M3 $\left(\lambda=0.55, \delta=-3.23\right.$ and $\left.\mathrm{R}^{2}=0.30\right)$, M5 $\left(\lambda=0.43, \mathrm{R}^{2}=0.19\right)$, M6 $\left(\lambda=0.51, \mathrm{SD}=0.94, \delta=-3.23\right.$ and $\left.\mathrm{R}^{2}=0.26\right)$ and $\mathrm{M} 7\left(\mathrm{R}^{2}=0.39\right)$ were considered low performing items. However, MOV exhibited a good fit after a modification was executed based on the suggestions in the Modification Indices (MI) of AMOS, using a threshold value of four. The initial goodness of fit indices after items deletion were $\chi 2 / \mathrm{df}=8.637, \mathrm{AGFI}=0.892, \mathrm{IFI}=0.976, \mathrm{TLI}=0.926$ and $\mathrm{CFI}=0.975$. The $\mathrm{RMR}=0.051, \mathrm{PNFI}=0.324$ and the value of RMSEA $=0.138$ which did not exhibit a good fit. After correlating the error terms of e 8 from the item 
M8 "My parents are very enthusiastic about my education" and e4 from the item M4 "When I do not get good grades, my parents will encourage me to try harder" which logically were related as suggested by the MI, the

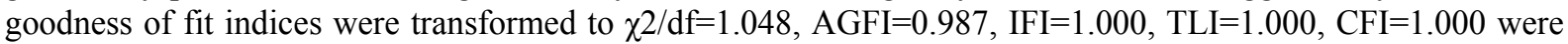
excellent fit and RMR $=0.009$ which was far below the criteria of $<0.05$ and PNFI $=0.166$ which was good and RMSEA $=0.011$ which was far below the criteria $<0.05$ to indicate an excellent fit. From a substantive meaningfulness, it could be expected that enthusiastic parents would always be concerned of their child's academic achievement and would encourage them to do their best in their examinations.

For the Warmness (WARM) construct, items $\mathrm{W} 1\left(\delta=3.14, \mathrm{R}^{2}=0.17\right), \mathrm{W} 2(\delta=3.14), \mathrm{W} 5(\lambda=0.57, \mathrm{SD}=1.08)$, $\mathrm{W} 6\left(\lambda=0.58, \mathrm{SD}=0.77\right.$ and $\left.\mathrm{R}^{2}=0.32\right), \mathrm{W} 7\left(\mathrm{R}^{2}=0.34\right)$ and $\mathrm{W} 8(\mathrm{SD}=1.06)$ showed some out of range values and were considered as probable items for deletion. However, due to the fact that at least four items were needed in CFA using AMOS, stepwise deletion was carried out to obtain a better composition of the items. This was also in accordance with recommendations in the literature suggesting that, if necessary, a poor performing item should be retained to satisfy statistical identification requirements or to meet the minimum numbered of items necessary per construct consideration (Hair et al., 2006). Finally, items W1, W2, W3 and W4 were retained.

Consequently, WARM yielded $\chi 2 / \mathrm{df}=1.092$, AGFI $=0.986, \mathrm{IFI}=1.000, \mathrm{TLI}=0.999, \mathrm{CFI}=1.000$ were well above the criteria value of $>0.90$ and $\mathrm{RMR}=0.010$ which was far below the criteria of $<0.05$ and $\mathrm{PNFI}=0.166$. The RMSEA $=0.015$ indicated an excellent fit. A modification was carried out as suggested by the MI for the WARM construct. The error, e3 of item W3 "How often do you watch television or play together (telling jokes, jogging, games etc.) with your family including your parents?" and the error, e4 of item W4 "I always inform my parents at home of any incidents, events or happenings in school." This showed some overlapping of errors as both items implied that the parent-child relationship was very good logically. However, this needs to be interpreted cautiously.

Lastly, the Conflict construct (CONF) exhibited poor factor loadings and five out of six of its item-total correlations were $<0.30$ cut off point. Since this was a new instrument, the researcher intended to keep some of the items for further investigation. Hence, a stepwise deletion beginning with the lowest factor loading was executed through CFA procedure and the best model that could be salvaged yielded the following indices, $\chi 2 / \mathrm{df}=4.353, \mathrm{AGFI}=0.968, \mathrm{IFI}=0.955, \mathrm{TLI}=0.909$ and $\mathrm{CFI}=0.954$. AGFI and TLI were above the cutoff value of $>0.90$. The $\mathrm{RMR}=0.047$ was below the criteria of $<0.05$ and PNFI $=0.471$. The RMSEA $=0.064$ indicated an acceptable fit. All the items were accepted except X4.

Overall, good fit was exhibited by all the constructs except CONF which was moderate in some of its goodness of fit indices. Twenty eight items were deleted in the process. Finally, a combination of 34 items was retained from the initial version of SPAQ1. This instrument is in its pupa stage of development and may need to further work in order to confirm the constructs stability and validity with proper norming.

All the eight constructs and items were subjected to the same procedure of item analysis processes. Confirmatory factor analysis (CFA) was used as a mean of scale reduction by showing which items can be trimmed from the scale (Netemeyer, Bearden \& Sharma, 2003). The summary of the GOF indices for the eight hypothetical constructs was summarized in Table 3.

[Insert Table 3 here]

\subsection{Convergent and Discriminant Validity Evidence of SPAQ1}

Standardized factor loadings of $>0.60$ and Cronbach's Alpha of $>0.70$ were considered in assessing the convergent validity of the individual scales and the inter-factor canonical correlations were used to assess discriminant validity of the eight constructs as per recommendations in the literature (Hair et al., 2006). Items with standardized factor loadings $\lambda<0.60$ were identified easily from the graphics output from AMOS 16.0. Each of the improvised dimensions and its factor loadings were explained as follow.

All the standardized factor loadings of ASP (refer to Figure 3) were well above the 0.60 criteria, hence implicating convergent validity of the items towards the ASP construct. In other words, all the different items in one way or another assessed the construct they intended to measure (Sarafino, 2005). Simultaneously, the GOF measures such as the AGFI, IFI, TLI, CFI, RMR, PNFI and RMSEA were in the acceptable range. The Cronbach's Alpha, $\alpha=0.83$ met the criteria. Hence, it was concluded that the construct ASP supported convergent validity.

The CFA results for HWK were summarized in Table 3 as well. As shown, all the factor loadings were above $\lambda=0.60$ except item $\mathrm{H} 1$ which was marginally low. But this was still indicative of convergent validity as suggested in Kline (2005) and Sarafino (2005) that the value of $\lambda=0.50$ was also considered sufficient. The rest 
of the GOF measures were fairly good and the Cronbach's Alpha value for HWK construct was 0.81. In short, the Homework construct supported convergent validity as well.

Overall, the COND construct exhibited a good fit and convergent validity was shown. The AGFI, IFI, TLI and CFI indices were all closed to 1.00 indicating a good fit. RMSEA was less than 0.05 , hence indicating an excellent fit of the model. The reliability coefficient, Cronbach's Alpha $\alpha=0.71$ which was slightly above the 0.70 and it fulfilled the criteria set for newly developed instrument recommended by Nunnally (1978). Therefore, convergent validity evidence was indicated from the statistics obtained.

The REL construct showed strong convergent validity. The factor loadings for each items was fairly good in strength. All were above 0.70 though the criteria set was only 0.60 . The GOF values showed good fit while the RMSEA fell within the range of below 0.80 . The $\alpha$-value for the subscale of REL was 0.89 . It can be concluded that these items and the construct indicated convergent validity. Results were summarized in Table 3.

The number of items in the CONT construct was revised to five items to achieve a good fit as shown in Table 3 . Though Item $\mathrm{C} 1 \mathrm{did}$ not achieve the criteria of $\lambda>0.60$, it was maintained as the researcher deemed it an important item and further investigation may need to be carried out. Item $\mathrm{C} 1$ says "How often do your parents ask you about your friends in school and after school?" The reliability alpha coefficient was $\alpha=0.76$. It can be concluded that this dimension exhibited convergent validity as well.

The MOV construct as shown in Figure 4 earlier, had fulfilled all the prerequisites GOF as well. The Cronbach's Alpha, 0.84 also implicated a high reliability value. Hence, convergent validity was supported.

The WARMNESS construct (in Table 3) needed to be modified as to improve its model fit. A correlation between the errors e4 and e5 was made based on the recommendation in the Modification Indices of AMOS. A review of the two items showed that there was possible overlapping as item W3 which states "How often do you watch television or play together (telling jokes, jogging, games etc.) with your family including your parents?" and W4 "I always inform my parents at home of any incidents, events or happenings in school. However, this interpretation has to be view cautiously. The Cronbach's Alpha value was $\alpha=0.77$. Overall, the above seven dimensions or constructs had exhibited convergent validity.

The final dimension was the CONFLICT (CONF) construct, drew a low reliability coefficient of $\alpha=0.52$. Though the GOF indices indicated a good fit but all the factor loadings were below the critical value of $\lambda>0.50$ except for item X1 $(\lambda=0.54)$. Hence, it can be concluded that this construct showed marginal convergent validity. This suggests further revision of this dimension is needed. This was tested stepwise by the researcher and the summarized results obtained were shown in Table 3. This was the best solution obtainable. Further investigation needs to be carried out to further test the suitability of the items.

Discriminant validity was determined by examining the canonical correlations between the dimensions. As suggested by Kline (2005), correlations less than 0.85 were considered not significant. In short it was assumed that items under the factors correlated were not duplicating. Based on the cutoff point of correlation $\mathrm{r}<0.85$ (Kline, 2005), there was a high correlation between WARM and MOV constructs. The correlation value between the WARM and MOV constructs was $r=0.88$ which exceeded the cut off value of $r<0.85$. This suggested that the items from the different dimensions were actually measuring the same thing, hence duplication might occurred. In order to overcome this problem, re-specification of the model was carried out.

The two dimensions, WARM and MOV were consolidated and renamed as CLOSENESS (CLOS). Consolidation of the two factors was done due to the fact that item deletion procedure was not feasible for the two constructs as the number of indicators or items left were the minimum needed for model identification using AMOS software application.

Comparatively, the re-specified model has a better model fit. As a comparison, Table 4 showed the GOF from the CFA of the two measurement models. Results in Table 4 showed the re-specified model AGFI had increased from 0.799 to 0.818 which still cannot be classified to be in the range of good fit $(>0.900)$, The RMR value had decreased, which was a sign of improvement as it was getting nearer to the range bound around 0.05 to be considered good. The IFI had also improved from 0.869 to 0.905 . PNFI had also decreased from 0.750 to 0.726 which was an indication of parsimonious. The CFI too had achieved better fit after the re-specification. The TLI had also improved from 0.869 to 0.893 . The RMSEA which was already within the fit range in the original model improved further to a value of 0.056 .

[Insert Table 4 here]

Overall, the re-specified model exhibited convergent validity evidence for all its indicators to the related dimensions. The re-specified model provided better discriminant validity indices. 


\subsection{Model fit of the re-specified SPAQ1}

In order to assess the overall model fit of the 34 items instrument, the seven dimensions were assessed using the second order measurement model. The parents' actions was assumed to be multidimensional and this was shown to be acceptable through the overall model fit assessment (refer to Figure 4). The $\chi 2 / \mathrm{df}=2.322$, AGFI $=0.805$, $\mathrm{RMR}=0.090, \mathrm{CFI}=0.889, \mathrm{TLI}=0.879$ and $\mathrm{RMSEA}=0.06$ ( with the $90 \%$ confidence interval from 0.055 to 0.064 ). Maximum likelihood was used as the method of estimation. The graphical results were as shown in Figure. 4.

[Insert Figure 4 here]

Though the overall GOF did not show a good fit as most of the indices indicated slight missed from the standard cutoff values, one have to bear in mind that this may be due to the marginal sample size of this study. A larger sample size may be needed in order to obtain a more stable result.

[Insert Table 5 here]

The unstandardized regression weights of all the parameters were significant at $\mathrm{p}<0.001$ (refer to Table 5). Hence, it can be concluded that all the seven constructs under investigation were relevant to parental actions. The beta weight $(\beta)$ for each of the construct were $\beta_{\mathrm{ASP}}=0.84, \beta_{\mathrm{HWK}}=0.91, \beta_{\mathrm{COND}}=0.77, \beta_{\mathrm{REL}}=0.84, \beta_{\mathrm{CONT}}=0.81, \beta_{\mathrm{CLOS}}=0.88$ and finally $\beta_{\mathrm{CONF}}=0.57$. By referring to the squared multiple correlations in Table 6 , it is estimated that the predictors of CLOS explain 77.3 percent of its variance. In other words, the error variance of CLOS is approximately 22.7 percent. Briefly, the variance explained for the seven constructs ranged from $32.7 \%$ to $83 \%$. .

\section{Conclusion}

The results obtained from this study showed that parents' actions towards their children are multidimensional in nature. The multidimensional parents' actions consisted of Aspiration, Homework, Conduciveness, Religiosity, Control, Conflict and Closeness, were operationalized by SPAQ1. The Malay version of the SPAQ1 consisted 34 items was able to tap the multidimensional structure of parental action as it exhibited acceptable psychometric properties of measurement.

Further investigations and replications would be necessary to provide a standard norm for the instrument. The validation of the measurement model of SPAQ1 had led to the accessibility of information on parental actions towards their adolescent school going children with the use of students' self-report questionnaire. More importantly, the analyses clearly implied that parents' actions towards their children were of multidimensional structure and SPAQ1 can be further explored for its utility.

\section{Limitations of the study}

The boundaries and limitations of this study were basically due to time, financial and feasibility constraints. The proposed hypothesized conceptual model was a priori model based on literatures and theories and the understanding of the researcher. This model was synergized after a thorough review of vast related literature based on parental involvement with school children overseas since literature was scarcely found locally in Malaysia.

Due to the fact that SPAQ1 was meant to be administered in schools and classrooms which would take up most of the students and teachers' lesson time, the researcher tried to ensure that the length of the questionnaire was acceptable and practical to be implemented. Therefore the indicators used could not be fully representative of all the dimensions in SPAQ1. This may limits the insight of the dimensional structure of parents' actions towards students' academic achievement.

Another limitation was the sample size used and limitation of geographical area. The research was carried out in the district of Southern Penang, Malaysia. Only six schools were selected based on convenience sampling for this study. Hence, inferential result may not be applicable and the power of the statistical analysis may be affected as well.

\section{Suggestions for further research}

Based on the results of this study, the following recommendations for future research could be formulated. Firstly, the final model of SPAQ1 should be tested. Further validation of the model will enhance the definition of the parents' actions dimensions towards their teenage children - adolescent academic outcomes in school. The newly developed instrument should be further investigated empirically in a larger scale. This serves to verify the scale reliability and further establish scale validity. Utilization of SPAQ1 in determining the relationships of the various dimensions of parents' actions and students' academic achievement and discipline can now be expedited. This will examine the congruency of the instrument and its function. It is also important that a study of the 
instrument invariance be carried out in a multi-ethnic society in Malaysia.

SPAQ1 could also be adapted to measure its influence over students' self concept and may become a useful quantitative tool in investigating parental involvement with adolescence students. Lastly, SPAQ1 should be applied in other geographical areas and sample populations to test for its stability and validity over time.

\section{References}

Arbuckle, J. L. (2007). AMOS 16.0. Amos Development Corporation, Spring House:US

Bandura, A. (1977). Self-efficacy toward a unifying theory of behavioral change. Psychological Review, 84, 191-215.

Bandura, A. (1989). Human agency in social cognitive theory: An agentive perspective. American Psychologist, 44, 1175-1184.

Blunch, N. J. (2008). Introduction to structural equation modeling using SPSS and AMOS. London: Sage publications.

Bollen, K. A. (1989). Structural equations with latent variables. New York: John Wiley \& sons.

Bowlby, J. (1969/1997). Attachment and loss: Attachment (Vol. 1). London: Pimlico.

Brislin, R. W. (1986). The wording and translation of research instruments. In W.J. Lonner \& J.W. Berry (Eds.), Field methods in cross-cultural research (p.137-164). Newsbury Park, CA: Sage

Bronfenbrenner, U. (1977). Toward an experimental ecology of human development. American Psychologist. 513-531.

Cooper, H., Lindsay, J. J., \& Nye, B. (2000). Homework in the home: How student, family, and parenting-style differences relate to the homework process. Contemporary Educational Psychology, 25(4), 464-487.

Couch, A., \& Keniston, K. (1960). Yeesayers and naysayers: Agreeing response set as a personality variable. Journal of Abnormal and Social Psychology, 60, 151-174.

Cronbach, L. J. (1946). Response sets and test validity. Educational and Psychological Measurement, 6, 475-494.

Epstein, J. L., Simon B. S., \& Salinas, K. C. (1997). Involving parents in homework in the middle grades. Research Bulletin, 18. Retrieved April 16th, 2009, from http://www.pdkintl.org/research/rbulletins/resbul18.htm

Fallon, B., \& Bowles, T. (1997). The effect of family structure and family functioning on adolescents' perceptions of intimate time spent on adolescents' perceptions of intimate time spent with parents, siblings, and peers. Journal of Youth \& Adolescence, 26(1), 25-44.

Hair, J. F., Black, W. C., Babin, B. J., Anderson, R. E., \& Tatham, R. L. (2006). Multivariate data analysis. Upper saddle River, New Jersey: Prentice Hall

Hirschi, T. (1969). Causes of Delinquency. University of California Press, Berkeley, CA.

Hong, S., \& Ho, H. (2005). Direct and indirect longitudinal effects of parental involvement on student achievement: Second order latent growth modeling across ethnic groups. Journal of Educational Psychology, 97(1), 16.

Joreskog, K. G.. \& Sorbom, D. (1984). Lisrel-VI, User's guide (3rd ed.). Mooresville, IN: Scientific Software.

Kline, R.B. (2005). Principles and practice of structural equation modeling (2nd edition). London: The Guilford Press.

Lee, S.-Y. (2007). Handbook of latent variable and related models. Elsevier: UK.

McLaughlin, M. D. (2006). "An analysis of the relationship between parental involvement and student achievement in Rhode Island elementary schools", (Unpublished Thesis), Johnson and Wales University, Providence.

Netemeyer, R. G.., Bearden, W. O., \& Sharma, S. (2003). Scaling procedures: Issues and applications. Thousand Oaks: Sage Publications.

Nunnally, J. C. (1978). Psychometric theory (2nd ed.). New York: McGraw-Hill.

Sarafino, E. P. (2005). Research methods: Using processes and procedures of science to understand behavior. Upper Saddle River, NJ: Pearson Prentice Hall. 
Tabachnick, B. G., \& Fidell, L. S. (2001). Using multivariate statistics (4th ed.). Boston, MA: Allyn \& Unwin.

Vijver, van de F. \& Leung, K. (1997). Methods and data analysis for cross-cultural research. Thousand Oaks, California: Sage Publications, 40-51.

Table 1. Samples ethnics, gender, GPA and age

\begin{tabular}{|c|c|c|c|c|c|c|c|c|}
\hline \multirow{2}{*}{ Ethnic } & \multirow{3}{*}{ Freq } & \multicolumn{6}{|c|}{ Gender } & \multirow{3}{*}{$\frac{\text { Age (years) }}{\text { Average }}$} \\
\hline & & \multicolumn{3}{|c|}{ Male } & \multicolumn{3}{|c|}{ Female } & \\
\hline GPA & & High & Low & Total & High & Low & Total & \\
\hline MLY & 142 & 7 & 43 & 50 & 29 & 63 & 92 & 16.36 \\
\hline $\mathrm{CHI}$ & 153 & 24 & 53 & 77 & 27 & 49 & 76 & 16.31 \\
\hline IND & 85 & 10 & 27 & 37 & 10 & 38 & 48 & 16.34 \\
\hline Total & 380 & 41 & 123 & 164 & 66 & 150 & 216 & 16.41 \\
\hline
\end{tabular}

Note. Freq=frequency, GPA=grade point average, MLY=Malay ethnic, $\mathrm{CHI}=$ Chinese, IND $=$ Indian. High GPA refers to GPA $<2.5$ and Low refers to GPA $>2.5$. GPA is the Grade Point Average of the PMR examination. $\mathrm{N}=380$

Table 2. Reliability, factor loadings, item-total correlations, and standardized residual covariances

\begin{tabular}{|c|c|c|c|c|c|c|c|}
\hline \multirow{2}{*}{ Constructs } & \multicolumn{2}{|c|}{ Items } & \multirow{2}{*}{$\begin{array}{c}\text { Item with } \\
\lambda<0.60\end{array}$} & \multirow{2}{*}{$\begin{array}{l}\alpha \text { if item } \\
\text { deleted }\end{array}$} & \multirow{2}{*}{$r_{i-i}$} & \multirow{2}{*}{$r_{i-t}$} & \multirow{2}{*}{$|\delta|$} \\
\hline & $\mathrm{SD}>1.10$ & $\mathrm{SD}<1.10$ & & & & & \\
\hline $\begin{array}{c}\text { Aspirations(ASP) } \\
\begin{array}{c}7 \text { items, A1-A7 } \\
\alpha=0.86\end{array}\end{array}$ & $\begin{array}{l}\text { A1,A3, } \\
\text { A4,A5, } \\
\text { A7 }\end{array}$ & $\begin{array}{l}\mathrm{A} 2=0.096 \\
\mathrm{~A} 6=0.083\end{array}$ & $\begin{array}{l}\mathrm{A} 2=0.54 \\
\mathrm{~A} 6=0.54\end{array}$ & $\begin{array}{l}\mathrm{A} 2=0.84 \\
\mathrm{~A} 6=0.84\end{array}$ & $\begin{array}{c}0.30-0 . \\
62\end{array}$ & $\begin{array}{c}0.51- \\
0.72\end{array}$ & $\mathrm{~A} 6 \& \mathrm{~A} 2=2.47$ \\
\hline $\begin{array}{c}\text { Homework }(\mathrm{HWK}) \\
7 \text { items, H1-H7 } \\
\alpha=0.84\end{array}$ & $\begin{array}{l}\mathrm{H} 1, \mathrm{H} 2, \\
\mathrm{H} 3, \mathrm{H} 4, \\
\mathrm{H} 5, \mathrm{H} 6\end{array}$ & $\mathrm{H} 7=1.03$ & $\begin{array}{l}\mathrm{H} 3=0.33 \\
\mathrm{H} 7=0.58\end{array}$ & $\begin{array}{l}\mathrm{H} 3=0.83 \\
\mathrm{H} 7=0.80\end{array}$ & $\begin{array}{c}0.21-0 . \\
71\end{array}$ & $\begin{array}{c}0.32- \\
0.64\end{array}$ & $\mathrm{H} 7 \& \mathrm{H} 1=2.34$ \\
\hline $\begin{array}{c}\text { Conducive(COND) } \\
7 \text { items, CD1-CD7 } \\
\alpha=0.71\end{array}$ & $\begin{array}{l}\mathrm{CD} 1, \mathrm{CD} 3, \\
\mathrm{CD} 4, \mathrm{CD} 5, \\
\mathrm{CD} 6, \mathrm{CD} 7\end{array}$ & $\mathrm{CD} 2=1.04$ & $\begin{array}{l}\mathrm{CD} 2=0.49 \\
\mathrm{CD} 4=0.40 \\
\mathrm{CD} 5=0.30 \\
\mathrm{CD} 7=0.44\end{array}$ & $\begin{array}{l}\mathrm{CD} 2=0.67 \\
\mathrm{CD} 4=0.70 \\
\mathrm{CD} 5=0.72 \\
\mathrm{CD} 7=0.68\end{array}$ & $\begin{array}{c}0.04-0 . \\
45\end{array}$ & $\begin{array}{c}0.24- \\
0.57 \\
(\mathrm{CD} 5)_{\mathrm{L}} \\
=0.24\end{array}$ & - \\
\hline 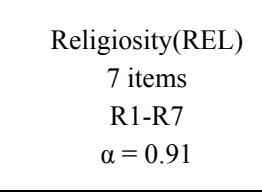 & $\begin{array}{c}\text { R1,R2, } \\
\text { R3,R4, } \\
\text { R5,R6 } \\
\text { R7 } \\
(\mathrm{R} 4=1.14)_{\mathrm{L}}\end{array}$ & - & - & $\mathrm{R} 4=0.90$ & $\begin{array}{c}0.47-0 . \\
73\end{array}$ & $\begin{array}{c}0.67- \\
0.83\end{array}$ & $\mathrm{R} 4 \& \mathrm{R} 2=1.53$ \\
\hline $\begin{array}{l}\text { Control(CONT) } \\
\begin{array}{c}12 \text { items } \\
\text { C1-C12 } \\
\alpha=0.86\end{array}\end{array}$ & $\begin{array}{c}\mathrm{C} 1, \mathrm{C} 3, \\
\mathrm{C} 4, \mathrm{C} 5, \\
\mathrm{C} 6, \mathrm{C} 7, \\
\mathrm{C} 8, \mathrm{C} 9, \\
\mathrm{C} 10, \mathrm{C} 11, \\
\mathrm{C} 12\end{array}$ & $\mathrm{C} 2=1.05$ & $\begin{aligned} \mathrm{C} 1 & =0.57 \\
\mathrm{C} 2 & =0.58 \\
\mathrm{C} 3 & =0.56 \\
\mathrm{C} 6 & =0.54 \\
\mathrm{C} 7 & =0.46 \\
\mathrm{C} 8 & =0.54 \\
\mathrm{C} 12 & =0.53\end{aligned}$ & $\begin{aligned} \mathrm{C} 1 & =0.85 \\
\mathrm{C} 2 & =0.85 \\
\mathrm{C} 3 & =0.85 \\
\mathrm{C} 6 & =0.86 \\
\mathrm{C} 7 & =0.86 \\
\mathrm{C} 8 & =0.85 \\
\mathrm{C} 12 & =0.86\end{aligned}$ & $\begin{array}{c}0.16-0 . \\
65\end{array}$ & $\begin{array}{c}0.42- \\
0.67\end{array}$ & $\begin{aligned} \mathrm{C} 1 \& \mathrm{C} 2 & =3.28 \\
\mathrm{C} 1 \& \mathrm{C} 4 & =3.57 \\
\mathrm{C} 4 \& \mathrm{C} 12 & =3.03 \\
\mathrm{C} 6 \text { \& } \mathrm{C} 12 & =3.91 \\
\mathrm{C} 7 \& \mathrm{C} 8 & =3.29\end{aligned}$ \\
\hline $\begin{array}{c}\text { Motivation(MOV) } \\
8 \text { items } \\
\text { M1-M8 } \\
\alpha=0.86\end{array}$ & $\begin{array}{c}\text { M1,M2, } \\
\text { M3,M4, } \\
\text { M5,M7, } \\
\text { M8 }\end{array}$ & M6 $=0.94$ & $\begin{array}{l}M 3=0.55 \\
M 5=0.43 \\
M 6=0.51\end{array}$ & $\begin{array}{l}M 3=0.84 \\
M 5=0.85 \\
M 6=0.84\end{array}$ & $\begin{array}{c}0.15-0 . \\
75\end{array}$ & $\begin{array}{c}0.41- \\
0.71\end{array}$ & M3 \& M6=3.23 \\
\hline $\begin{array}{c}\text { Warm(WARM) } \\
8 \text { items } \\
\text { W1-W8 } \\
\alpha=0.83\end{array}$ & $\begin{array}{l}\text { W1, } \\
\text { W3, } \\
\text { W4 }\end{array}$ & $\begin{array}{l}\mathrm{W} 5=1.08 \\
\mathrm{~W} 6=0.77 \\
\mathrm{~W} 8=1.06\end{array}$ & $\begin{array}{l}\mathrm{W} 5=0.57 \\
\mathrm{~W} 6=0.58 \\
\mathrm{~W} 8=0.41\end{array}$ & $\begin{array}{l}\mathrm{W} 5=0.79 \\
\mathrm{~W} 6=0.80 \\
\mathrm{~W} 7=0.79 \\
\mathrm{~W} 8=0.81\end{array}$ & $\begin{array}{c}0.25-0 . \\
64\end{array}$ & $\begin{array}{c}0.37- \\
0.59\end{array}$ & $\begin{array}{l}\mathrm{W} 1 \& \mathrm{~W} 2=3.14 \\
\mathrm{~W} 6 \& \mathrm{~W} 8=2.28\end{array}$ \\
\hline $\begin{array}{c}\text { Conflict(CONF) } \\
6 \text { items } \\
\text { X1-X6 } \\
\alpha=0.56\end{array}$ & $\begin{array}{l}\mathrm{X} 1, \mathrm{X} 2 \\
\mathrm{X} 4, \mathrm{X} 5 \\
\mathrm{X} 6\end{array}$ & $\mathrm{X} 3=1.05$ & $\begin{array}{l}X 4=0.30 \\
X 2=0.33 \\
X 3=0.37 \\
X 6=0.39 \\
X 5=0.47 \\
X 1=0.59\end{array}$ & $\begin{array}{l}X 4=0.53 \\
X 2=0.52 \\
X 3=0.51 \\
X 6=0.53 \\
X 5=0.49 \\
X 1=0.46\end{array}$ & $\begin{array}{c}0.009- \\
0.29\end{array}$ & $\begin{array}{c}0.21- \\
0.39\end{array}$ & $X 4 \& X 6=2.11$ \\
\hline
\end{tabular}

Note. $\mathrm{SD}=$ standard deviation, $\alpha=$ Cronbach's alpha coefficient, $\lambda=$ factor loading, $\mathrm{r}_{\mathrm{i}-\mathrm{i}}=$ inter - item correlations, $\mathrm{r}_{\mathrm{i}-\mathrm{t}}=$ item-total correlations, $\delta=$ standardized residual covariances, ( ) $)_{\mathrm{L}}$ indicates the lowest value of the parameter. 
Table 3. Summary of Confirmatory Factor Analysis results for each individual constructs before and after item analysis.

\begin{tabular}{|c|c|c|c|c|c|c|}
\hline Constr & Item & $\begin{array}{l}\text { Initial Goodness of Fit Indices } \\
\text { (GOF) }\end{array}$ & Constr & Item & $\lambda$ & Final GOF after item deletion \\
\hline \multirow{4}{*}{$\begin{array}{c}\text { ASP } \\
\alpha=0.86\end{array}$} & \multirow{4}{*}{$\begin{array}{c}\mathrm{A} 1-\mathrm{A} 7 \\
\lambda=0.54 \\
-0.79\end{array}$} & \multirow{4}{*}{$\begin{array}{l}\chi^{2} / \mathrm{df}=4.507, \text { AGFI }=0.900, \\
\mathrm{RMR}=0.050, \mathrm{IFI}=0.951, \\
\mathrm{TLI}=0.925, \text { PNFI }=0.625, \\
\mathrm{CFI}=0.950, \mathrm{RMSEA}=0.097\end{array}$} & \multirow{4}{*}{$\begin{array}{c}\text { ASP } \\
\alpha=0.85\end{array}$} & A1 & 0.760 & \multirow{4}{*}{$\begin{array}{l}\chi^{2} / \mathrm{df}=1.956, \mathrm{AGFI}=0.976, \\
\mathrm{RMR}=0.021, \mathrm{IFI}=0.997, \\
\mathrm{TLI}=0.990, \mathrm{PNFI}=0.331, \\
\mathrm{CFI}=0.997, \mathrm{RMSEA}=0.049\end{array}$} \\
\hline & & & & $\mathrm{A} 3$ & 0.670 & \\
\hline & & & & A4 & 0.800 & \\
\hline & & & & A5 & 0.750 & \\
\hline \multirow{4}{*}{$\begin{array}{c}\text { HWK } \\
\alpha=0.84\end{array}$} & \multirow{4}{*}{$\begin{array}{r}\mathrm{H} 1-\mathrm{H} 7 \\
\lambda=0.35 \\
-0.78\end{array}$} & \multirow{4}{*}{$\begin{array}{l}\chi^{2} / \mathrm{df}=9.892, \mathrm{AGFI}=0.787, \\
\mathrm{RMR}=0.085, \mathrm{IFI}=0.878, \\
\mathrm{TLI}=0.815, \mathrm{PNFI}=0.577, \\
\mathrm{CFI}=0.877, \mathrm{RMSEA}=0.155\end{array}$} & \multirow{4}{*}{$\begin{array}{c}\text { HWK } \\
\alpha=0.83\end{array}$} & H1 & 0.520 & \multirow{4}{*}{$\begin{array}{l}\chi^{2} / \mathrm{df}=2.127, \mathrm{AGFI}=0.975, \\
\mathrm{RMR}=0.025, \mathrm{IFI}=0.996, \\
\mathrm{TLI}=0.988, \mathrm{PNFI}=0.331, \\
\mathrm{CFI}=0.996, \mathrm{RMSEA}=0.053\end{array}$} \\
\hline & & & & $\mathrm{H} 2$ & 0.770 & \\
\hline & & & & $\mathrm{H} 4$ & 0.870 & \\
\hline & & & & $\mathrm{H} 5$ & 0.710 & \\
\hline \multirow{4}{*}{$\begin{array}{l}\text { COND } \\
\alpha=0.71\end{array}$} & \multirow{4}{*}{$\begin{array}{c}\quad \mathrm{CD} 1 \\
-\mathrm{CD} 7 \\
\lambda=0.27-0 \\
.67\end{array}$} & \multirow{4}{*}{$\begin{array}{l}\chi^{2} / \mathrm{df}=0.844, \mathrm{AGFI}=0.982, \\
\mathrm{RMR}=0.037, \mathrm{IFI}=1.000, \\
\mathrm{TLI}=1.000, \mathrm{PNFI}=0.648, \\
\mathrm{CFI}=1.000, \mathrm{RMSEA}=0.000\end{array}$} & \multirow{4}{*}{$\begin{array}{l}\text { COND } \\
\alpha=0.72\end{array}$} & $\mathrm{CD} 1$ & 0.660 & \multirow{4}{*}{$\begin{array}{l}\chi^{2} / \mathrm{df}=0.072, \mathrm{AGFI}=0.999, \\
\mathrm{RMR}=0.005, \mathrm{IFI}=1.000, \\
\mathrm{TLI}=1.000, \mathrm{PNFI}=0.333, \\
\mathrm{CFI}=1.000, \mathrm{RMSEA}=0.000\end{array}$} \\
\hline & & & & $\mathrm{CD} 2$ & 0.510 & \\
\hline & & & & $\mathrm{CD} 3$ & 0.660 & \\
\hline & & & & CD6 & 0.620 & \\
\hline \multirow{4}{*}{$\begin{array}{c}\text { REL } \\
\alpha=0.91\end{array}$} & \multirow{4}{*}{$\begin{array}{c}\mathrm{R} 1-\mathrm{R} 6 \\
\lambda=0.70-0 \\
.87\end{array}$} & \multirow{4}{*}{$\begin{array}{l}\chi^{2} / \mathrm{df}=5.556, \mathrm{AGFI}=0.881, \\
\mathrm{RMR}=0.057, \mathrm{IFI}=0.960, \\
\mathrm{TLI}=0.940, \mathrm{PNFI}=0.634, \\
\mathrm{CFI}=0.960, \mathrm{RMSEA}=0.111\end{array}$} & \multirow{4}{*}{$\begin{array}{c}\text { REL } \\
\alpha=0.89\end{array}$} & $\mathrm{R} 1$ & 0.830 & \multirow{4}{*}{$\begin{array}{l}\chi^{2} / \mathrm{df}=3.457, \mathrm{AGFI}=0.952, \\
\mathrm{RMR}=0.025, \mathrm{IFI}=0.994, \\
\mathrm{TLI}=0.983, \mathrm{PNFI}=0.331, \\
\mathrm{CFI}=0.994, \mathrm{RMSEA}=0.078\end{array}$} \\
\hline & & & & R3 & 0.860 & \\
\hline & & & & R6 & 0.740 & \\
\hline & & & & R7 & 0.810 & \\
\hline \multirow{5}{*}{$\begin{array}{l}\text { CONT } \\
\alpha=0.86\end{array}$} & \multirow{5}{*}{$\begin{array}{c}\mathrm{C} 1-\mathrm{C} 12 \\
\lambda=0.43-0 \\
.77\end{array}$} & \multirow{5}{*}{$\begin{array}{c}\chi^{2} / \mathrm{df}=5.434, \mathrm{AGFI}=0.817, \\
\mathrm{RMR}=0.096, \mathrm{IFI}=0.851, \\
\mathrm{TLI}=0.817, \mathrm{PNFI}=0.674, \\
\mathrm{CFI}=0.850, \mathrm{RMSEA}=0.109\end{array}$} & \multirow{5}{*}{$\begin{array}{l}\text { CONT } \\
\alpha=0.84\end{array}$} & $\mathrm{C} 1$ & 0.559 & \multirow{5}{*}{$\begin{array}{l}\chi^{2} / \mathrm{df}=1.953, \mathrm{AGFI}=0.973 \\
\mathrm{RMR}=0.046, \mathrm{IFI}=0.991, \\
\mathrm{TLI}=0.985, \mathrm{PNFI}=0.589, \\
\mathrm{CFI}=0.991, \mathrm{RMSEA}=0.049\end{array}$} \\
\hline & & & & C9 & 0.775 & \\
\hline & & & & $\mathrm{C} 10$ & 0.843 & \\
\hline & & & & $\mathrm{C} 11$ & 0.752 & \\
\hline & & & & $\mathrm{C} 12$ & 0.464 & \\
\hline \multirow{4}{*}{$\begin{array}{c}\mathrm{MOV} \\
\alpha=0.86\end{array}$} & \multirow{4}{*}{$\begin{array}{c}\mathrm{M} 1-\mathrm{M} 8 \\
\lambda=0.43-0 \\
.82\end{array}$} & \multirow{4}{*}{$\begin{array}{l}\chi^{2} / \mathrm{df}=6.496, \mathrm{AGFI}=0.835, \\
\mathrm{RMR}=0.071, \mathrm{IFI}=0.906, \\
\mathrm{TLI}=0.867 \text { PNFI }=0.636, \\
\mathrm{CFI}=0.905, \mathrm{RMSEA}=0.122\end{array}$} & MOV & M1 & 0.810 & $\chi^{2} / \mathrm{df}=1.048, \mathrm{AGFI}=0.987$ \\
\hline & & & $\alpha=0.84$ & M2 & 0.890 & $\mathrm{RMR}=0.009, \mathrm{IFI}=1.000$ \\
\hline & & & & M4 & 0.620 & $\mathrm{TLI}=1.000 \mathrm{PNFI}=0.166$ \\
\hline & & & & M8 & 0.600 & $\mathrm{CFI}=1.000, \mathrm{RMSEA}=0.011$ \\
\hline WARM & W1-W8 & $\chi^{2} / \mathrm{df}=5.679, \mathrm{AGFI}=0.872, \mathrm{RMR}=$ & WARM & W1 & 0.880 & $\chi^{2} / \mathrm{df}=1.092, \mathrm{AGFI}=0.986$ \\
\hline$\alpha=0.83$ & $\lambda=0.47-0$ & $0.061, \mathrm{IFI}=0.895, \mathrm{TLI}=0.852$ & $\alpha=0.77$ & W2 & 0.680 & $\mathrm{RMR}=0.010, \mathrm{IFI}=1.000$ \\
\hline & .68 & $\mathrm{PNFI}=0.626$ & & W3 & 0.480 & TLI=0.999, PNFI=0.166, \\
\hline & & $\mathrm{CFI}=0.894, \mathrm{RMSEA}=0.112$ & & W4 & 0.530 & $\mathrm{CFI}=1.000, \mathrm{RMSEA}=0.015$ \\
\hline $\mathrm{CONF}$ & X1-X6 & $\chi^{2} / \mathrm{df}=2.581, \mathrm{AGFI}=0.946$ & $\mathrm{CONF}$ & $\mathrm{X} 1$ & 0.540 & $\chi^{2} / \mathrm{df}=2.092, \mathrm{AGFI}=0.965$ \\
\hline$\alpha=0.56$ & $\lambda=0.31-0$ & $\mathrm{RMR}=0.065, \mathrm{IFI}=0.892$ & $\alpha=0.52$ & $\mathrm{X} 2$ & 0.470 & $\mathrm{RMR}=0.056, \mathrm{IFI}=0.938$ \\
\hline & .59 & $\mathrm{TLI}=0.812, \mathrm{PNFI}=0.506$ & & $\mathrm{X} 3$ & 0.480 & $\mathrm{TLI}=0.893, \mathrm{PNFI}=0.533$ \\
\hline & & $\mathrm{CFI}=0.887, \mathrm{RMSEA}=0.071$ & & $\mathrm{X} 5$ & 0.490 & $\mathrm{CFI}=0.936, \mathrm{RMSEA}=0.054$ \\
\hline & & & & $\mathrm{X} 6$ & 0.450 & \\
\hline
\end{tabular}

Note. Constr $=$ Construct, $\lambda=$ factor loading, $\chi^{2} / \mathrm{df}=$ chisquare upon degree of freedom

Table 4. Comparison of Goodness of fit indices

\begin{tabular}{|l|c|c|}
\hline GOF & $\begin{array}{c}\text { Original } \\
\text { model }\end{array}$ & Re-specified model \\
\hline$\chi^{2} / \mathrm{df}$ & 2.431 & 2.176 \\
\hline AGFI & 0.799 & 0.818 \\
\hline RMR & 0.088 & 0.084 \\
\hline CFI & 0.884 & 0.904 \\
\hline TLI & 0.869 & 0.893 \\
\hline RMSEA & 0.062 & 0.056 \\
\hline
\end{tabular}


Table 5. Regression Weights of SPAQ1 first order measurement model

\begin{tabular}{|c|c|c|c|c|c|l|}
\hline Construct & & & Est. & S.E. & C.R. & P \\
\hline COND & $<---$ & PA & 0.581 & 0.055 & 10.551 & $* * *$ \\
\hline REL & $<---$ & PA & 1.046 & 0.067 & 15.532 & $* * *$ \\
\hline CONT & $<---$ & PA & 0.557 & 0.060 & 9.366 & $* * *$ \\
\hline CLOS & $<---$ & PA & 0.708 & 0.045 & 15.869 & $* * *$ \\
\hline CONF & $<---$ & PA & 0.491 & 0.062 & 7.924 & $* * *$ \\
\hline HWK & $<---$ & PA & 0.722 & 0.056 & 12.816 & $* * *$ \\
\hline ASP & $<---$ & PA & 0.891 & 0.060 & 14.756 & $* * *$ \\
\hline
\end{tabular}

Note. $\mathrm{PA}=$ parents' actions, $\mathrm{COND}=$ conduciveness, $\mathrm{REL}=$ religiosity, $\mathrm{CONT}=$ control, $\mathrm{CLOS}=$ closeness, $\mathrm{CONF}=$ conflict, HWK=homework, $\mathrm{ASP}=$ aspiration, $* * *$ indicates significance at $\mathrm{p}<0.001$

Table 6. Squared multiple correlations of the related constructs

\begin{tabular}{|c|r|c|c|c|c|c|r|}
\hline Construct & CLOSE & ASP & COND & REL & HWK & CONF & CONT \\
\hline Estimate & 0.773 & 0.704 & 0.597 & 0.706 & 0.830 & 0.327 & 0.658 \\
\hline
\end{tabular}

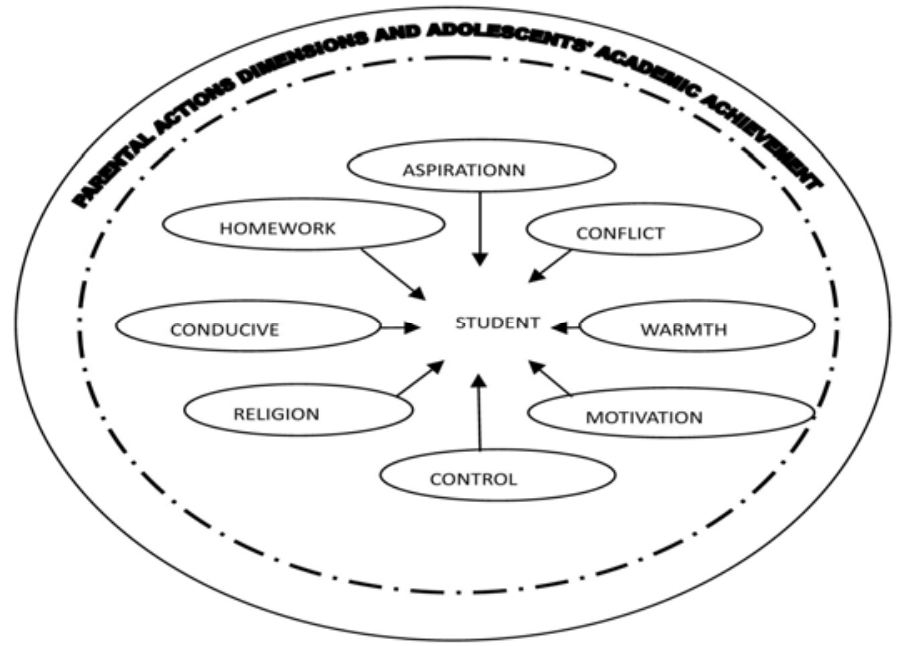

Figure 1. Theoretical framework of parents' action dimensions

\begin{tabular}{l} 
Dimension \\
\hline Aspirations(ASP) (7 items -coded \\
A1 to A7) \\
Homework (HWK) \\
(7 items- coded H1 to H7) \\
Conduciveness(COND) (7 \\
items-coded CD1 to CD7) \\
Religious Practice (REL) \\
(6 items-coded R1 to R6) \\
Control and monitoring(CON) \\
(12 items-coded C1 to C12) \\
Motivation(MOV) (8 items-coded M1 \\
to M8) \\
Warmth(WARM) \\
8 items-coded W1 to W8) \\
Conflict (CONF) (7 items-coded X1 \\
to X7)
\end{tabular}

\section{Brief definition}

Parents' expectation or hope for their children academic achievement and success.

Parents' involvement related to completing school work at home.

Parents' action in providing suitable home environment for children to do revision and other academic or school related activities.

Parents' religious practice and encouragement for their children to do the same. In the eastern culture, it is believed that one's success is granted by GOD.

Parents supervision of their children's activities such as who they befriended, their whereabout after school and setting certain rules that have to be adhered to.

Actions that parents do to encourage and motivate their child to be successful in academic achievement

Relationship between parents and their children. Frequent casual communication, togetherness in carrying out certain activities and the confidence of the child towards their parents.

Child's disagreement or unhappiness with parents' action

Figure 2. The eight hypothetical constructs operationalized for SPAQ1 measurement instrument. 


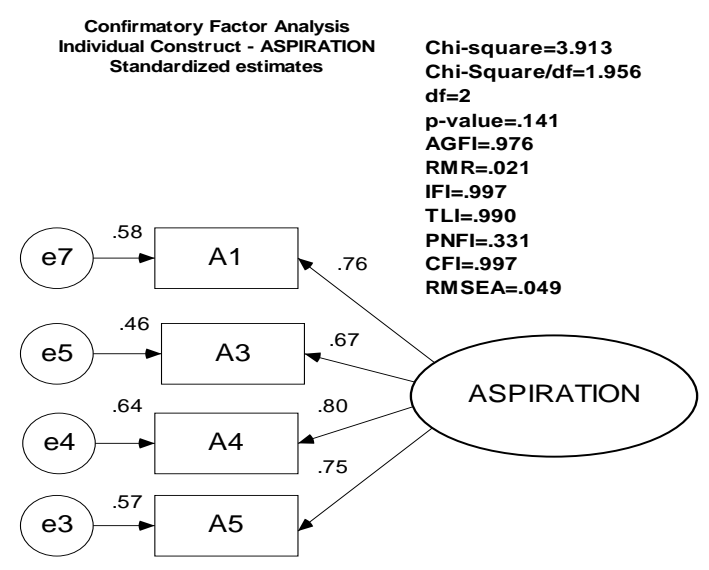

Figure 3. The ASPIRATION construct and the items after revision was carried out
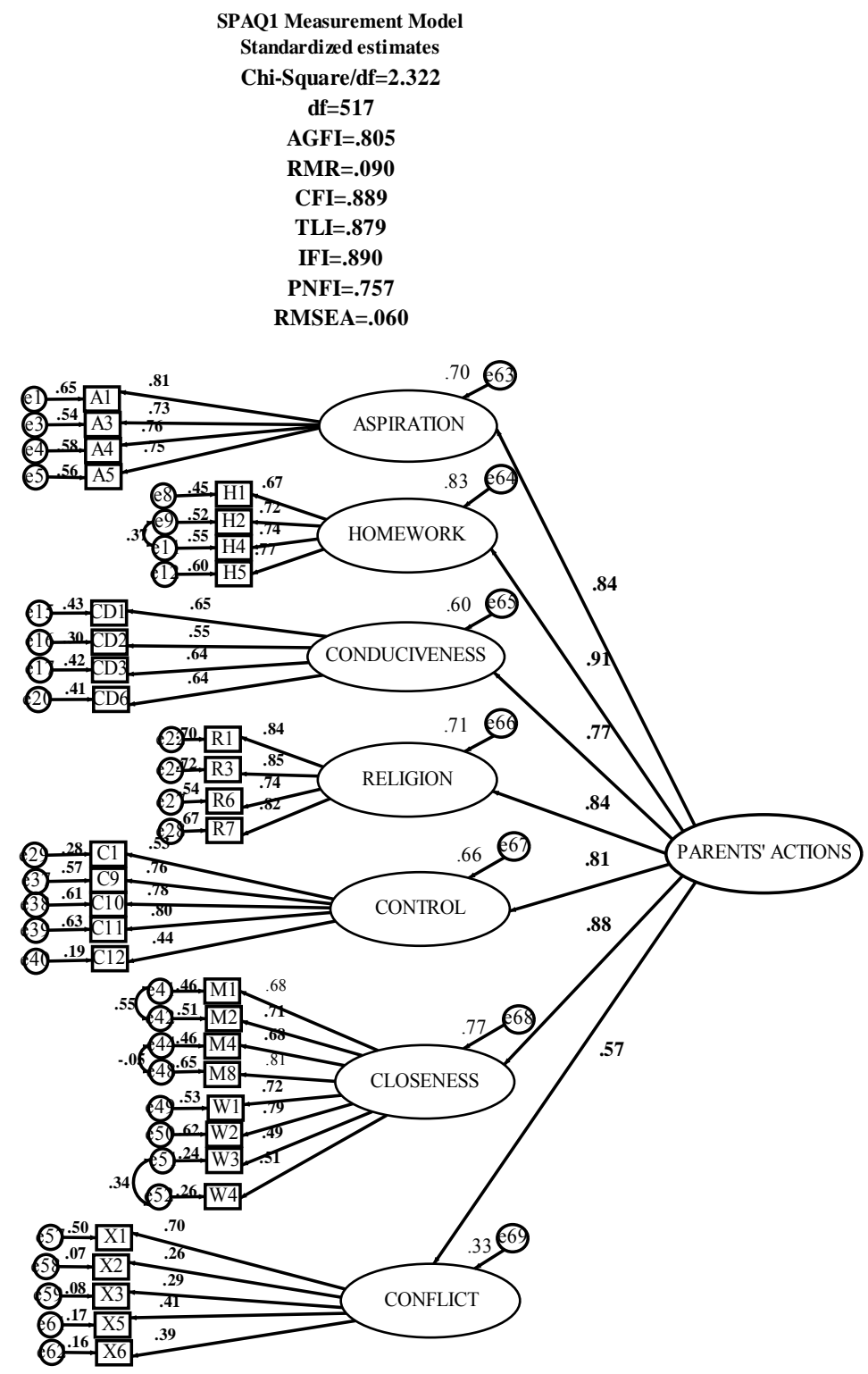

Figure 4. SPAQ1 second order measurement model. 